\title{
Usefulness of direct clipping for the bleeding source of colonic diverticular hemorrhage (with videos)
}

\section{다)(웅}

\author{
Authors \\ Takaaki Kishino, Kazuyuki Kanemasa, Yoko Kitamura, Kohei Fukumoto, Naoki Okamoto, Hideto Shimokobe
}

Institution

Department of Gastroenterology and Hepatology, Center for Digestive and Liver Diseases, Nara City Hospital, Nara, Japan

submitted 24.6.2019

accepted after revision 7.10 .2019

Bibliography

DOI https://doi.org/10.1055/a-1036-6077 |

Endoscopy International Open 2020; 08: E377-E385

(c) Georg Thieme Verlag KG Stuttgart · New York

eISSN 2196-9736

Corresponding author

Takaaki Kishino, MD, Department of Gastroenterology and Hepatology, Center for Digestive and Liver Diseases, Nara City Hospital, 1-50-1 Higashikideracho, Nara 630-8305, Japan

Fax: +81-742222478

t-kishino@nara-jadecom.jp

\section{ABSTRACT}

Background and study aims The efficacy of endoclips for colonic diverticular hemorrhage remains unclear. The aim of the current study was to evaluate the safety and efficacy of endoclips versus endoscopic band ligation (EBL) for the treatment of colonic diverticular hemorrhage.

Patients and methods At Nara City Hospital, 93 patients with colonic diverticular hemorrhage with stigmata of recent hemorrhage (SRH) were treated using endoclips or EBL between January 2013 and December 2018. We classified the patients treated by endoclips into the direct clipping group and indirect clipping group. Endoclips were placed directly onto the vessel if technically feasible (direct clipping). When direct placement of endoclips onto the vessel was not possible, the diverticulum was closed in a zipper fashion (indirect clipping). Patient demographics, rate of early rebleeding within 30 days after initial treatment, and complications were retrospectively evaluated.

Results Of the 93 patients, 34, 28, and 31 were in the direct clipping group, indirect clipping group, and EBL group, respectively. Rates of early rebleeding in the direct clipping, indirect clipping, and EBL groups were 5.9\% (2/34), 35.7\% $(10 / 28)$, and $6.5 \%(2 / 31)$, respectively $(P=0.006$ : direct clipping vs indirect clipping, $P=1$ : direct clipping vs $E B L)$. No complications occurred in any groups. All patients who had early rebleeding in the direct clipping group underwent $\mathrm{EBL}$, and no further bleeding occurred after repeat therapy. Conclusions Direct clip placement is acceptable as the first treatment choice for colonic diverticular hemorrhage. When direct placement of endoclips is not possible, EBL should be performed instead of indirect clipping.

\section{Introduction}

Diverticular hemorrhage accounts for approximately $20 \%$ to 48 $\%$ of lower gastrointestinal bleeding (LGIB) and is the most commonly identifiable cause of LGIB [1-3]. Incidence of diverticular hemorrhage has been increasing with growing use of antithrombotic drugs in elderly patients [4-7].

Diverticular hemorrhage has a less severe course than upper gastrointestinal bleeding and stops spontaneously in $70 \%$ to $80 \%$ of cases [ 3,8$]$. However, rebleeding occurs in approximately $25 \%$ of these patients, with some requiring medical intervention [3, 8-10]. Moreover, the recurrent bleeding rate in patients with stigmata of recent hemorrhage $(\mathrm{SRH})$ is reported to be relatively high (more than $60 \%$ ) with medication alone [11].
After identification of SRH, the current standard treatment for diverticular bleeding is endoscopic hemostasis $[11,12]$ achieved by clipping, endoscopic band ligation (EBL), endoscopic detachable snare ligation therapy (EDSL), injection therapy, or thermal contact. EBL has been used more frequently than clipping because the early recurrent bleeding rate after EBL is lower than that with clipping [13]. However, adverse events (AEs) after EBL, such as diverticulitis and perforation, have been reported, albeit rarely $[14,15]$.

The endoclip approach offers the theoretical advantage of causing less damage to adjacent tissues [16-18]. However, the efficacy of endoclips for diverticular bleeding remains unclear. In the current study, we retrospectively evaluated the safety 
and efficacy of endoclips versus EBL for treatment of colonic diverticular hemorrhage.

\section{Patients and methods}

\section{Study population}

This was a retrospective study of patients who underwent colonoscopy with a diagnosis of LGIB between January 2013 and December 2018 at Nara City Hospital. Definite colonic diverticular hemorrhage was evident in 96 of 493 patients, with SRH being observed. SRH was defined as a densely adherent clot despite vigorous irrigation, a non-bleeding visible vessel, or active bleeding visualized on colonoscopy, SRH allowed for unequivocal identification of a specific diverticulum as the source of bleeding $[19,20]$. In the first session, three of these patients were treated with transcatheter arterial embolization (TAE) instead of endoscopic therapy and 93 with endoscopic clipping or EBL. We classified the endoscopic clipping group into a direct clipping group and indirect clipping group. The current study was approved by the Institutional Review Board of Nara City Hospital and all patients provided informed consent before undergoing the procedure.

\section{Colonoscopic examinations}

All patients received standard supportive medical care for LGIB, including hemodynamic monitoring and fluid resuscitation. Packed red blood cells (RBCs) were transfused to correct severe anemia if necessary. Bowel preparation with polyethylene glycol or glycerin enema was performed before colonoscopic examinations. All patients underwent colonoscopy using waterjet scopes with a tip hood (PCF-Q260AZI or GIF-Q260 J: Olympus Optical Company Ltd., Tokyo, Japan), and a water-jet system was used for vigorous irrigation. To improve endoscopic visualization of colonic diverticula, we observed the colonic diverticulum under full water immersion [21] since 2016.

\section{Endoscopic hemostasis with endoclips (video)}

We classified clipping methods into direct and indirect clipping. In the direct clipping method, endoclips (HX-610-090S EZ CLIP; Olympus Optical Company Ltd.) were placed directly onto the vessel ( $\triangleright$ Fig.1a, $>$ Video $\mathbf{1}$ ). When direct placement of endoclips onto the vessel was not possible, the diverticulum was closed in a zipper manner ( $\mathbf{F i g} \mathbf{1 b}$ ). In the indirect clipping method, endoscopists selected the type of endoclips (HX-610-090S, HX-610-135, or HX-610-090 L, EZ CLIP; Olympus Optical Company Ltd.) based on the shape of the diverticulum ( Fig.2). In the current study, we distinguished between direct and indirect clip placement using endoscopic reports and colonoscopic images.

\section{Endoscopic hemostasis with EBL}

At our institution, we introduced EBL for colonic diverticular hemorrhage in February 2016. The method of EBL used for colonic diverticular hemorrhage was the same as that reported previously [13,22-24]. After the site of bleeding had been marked with endoclips, the colonoscope was removed and subsequently reinserted after attachment of a band-ligator device (MD-

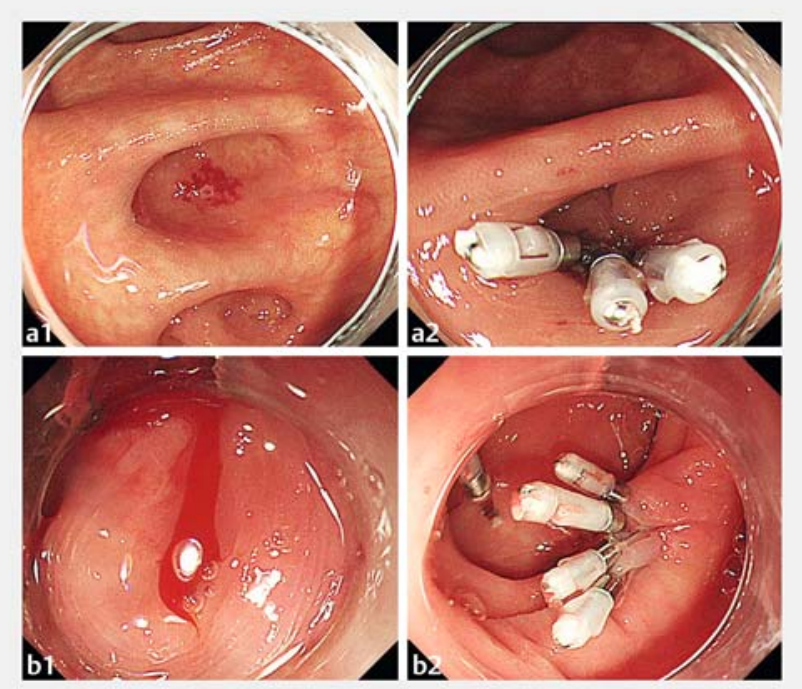

- Fig. 1 Endoscopic hemostasis with endoclips. a1 Colonic diverticulum with a non-bleeding visible vessel. a2 Endoclips were placed directly onto the vessel (direct clipping). b1 Active bleeding from the colonic diverticulum. b2 The diverticulum was closed in a zipper manner (indirect clipping).

48912S EHL Devices; Sumitomo Bakelite Company Ltd., Tokyo, Japan). The diverticulum was pulled via suction into the cup of the endoscopic ligator, and the elastic O-ring was released.

\section{Further treatment for rebleeding after initial endoscopic treatment}

Early rebleeding was defined as clinical evidence of recurrent LGIB within 30 days of initial treatment [19]. If rebleeding after initial endoscopic treatment occurred, a repeat endoscopic intervention was attempted. If diverticular rebleeding was not controlled by endoscopic retreatment, as in the case of massive rebleeding from previously treated diverticula, a poor endo-

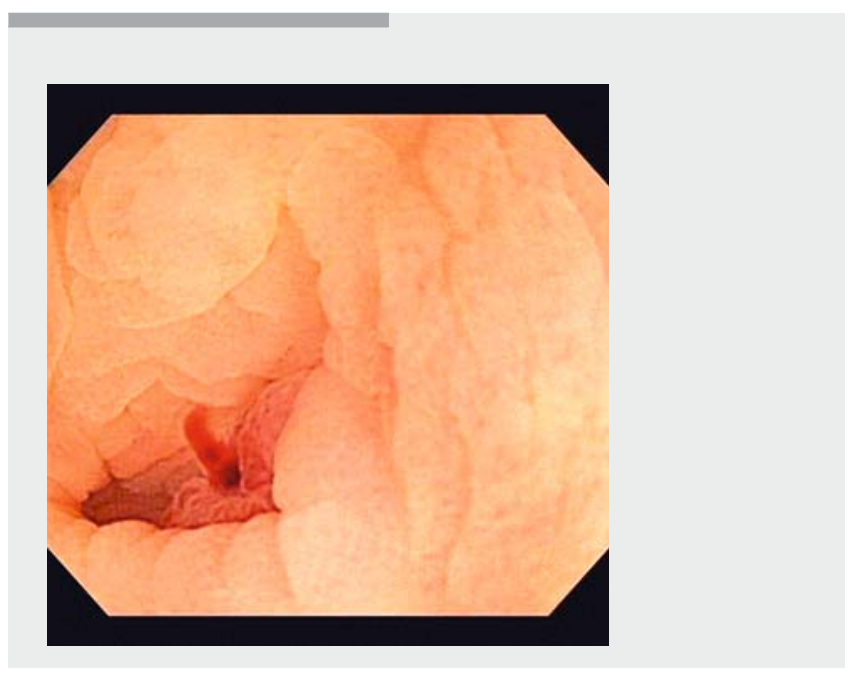

$\nabla$ Video 1 Direct clip placement. 


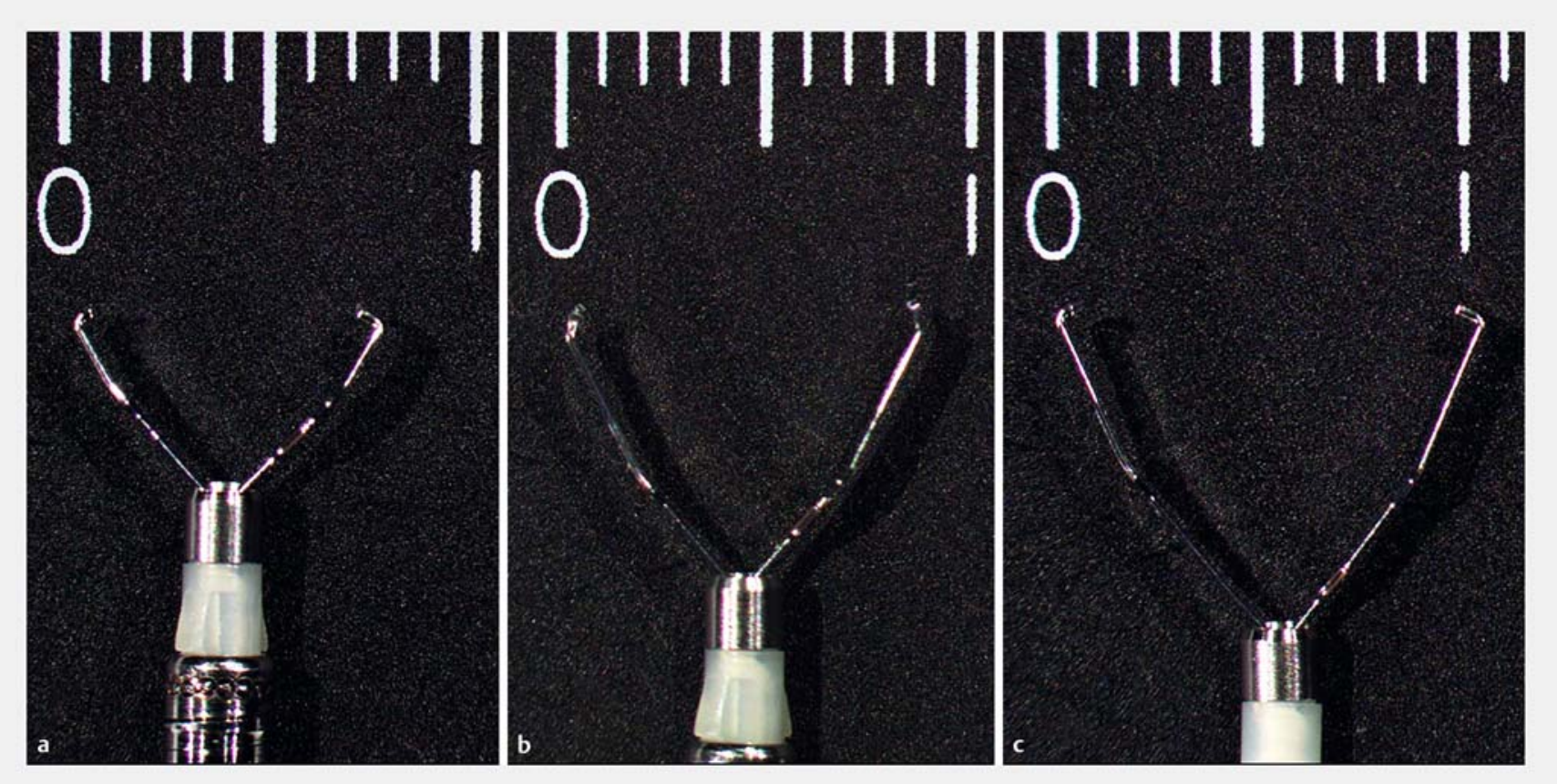

- Fig. 2 Types of endoclips. a HX-610-090S (short clip). b HX-610-135 (middle clip). c HX-610-090 L (long clip); EZ CLIP, Olympus Optical Company Ltd.

scopic view, or hemodynamic instability, TAE or colectomy was performed based on the clinical judgment of the attending gastroenterologist.

\section{Statistical analysis}

Ddemographics of patients, location of bleeding diverticula (cecum, ascending colon, transverse colon, descending colon, or sigmoid colon), bleeding point in the diverticulum (dome, neck, or unconfirmed), total procedural time, time to hemostasis after identification of the bleeding site, rate of early rebleeding, time to discharge after initial hemostasis, units of packed RBCs, and complications were retrospectively evaluated. Results obtained were expressed as medians (IQR, interquartile range) for continuous variables and proportions for categorical variables. A multilevel logistic regression analysis was performed to identify independent risk factors associated with early rebleeding, and odds ratios (ORs and 95\% confidence intervals (Cis) were calculated. The significance of differences was defined as $P<0.05$. All statistical analyses were performed with EZR (Saitama Medical Center, Jichi Medical University, Saitama, Japan), which is a graphical user interface for R (The R Foundation for Statistical Computing, Vienna, Austria). More precisely, it is a modified version of $\mathrm{R}$ commander designed to add statistical functions frequently used in biostatistics.

\section{Results}

\section{Patient characteristics}

Patient characteristics in the direct clipping, indirect clipping, and EBL groups are shown in $>$ Table 1. Among 93 patients, 34,28 , and 31 were in the direct clipping group, indirect clipping group, and EBL group, respectively. In the indirect clipping group, an initial injection of hypertonic saline epinephrine solution (HSE) for diverticula with active bleeding was used for four patients. No significant differences were observed in age of patients, percentage of males, rate of hypertension, hyperlipidemia, chronic kidney disease, or heart disease, usage of nonsteroidal anti-inflammatory drugs (NSAIDs) and steroids, a previous history of colonic diverticular hemorrhage, hematocrit on admission, or the shock index between the three groups. The rate of diabetes mellitus was higher in the EBL group $(P=0.043$ for the direct clipping group vs the EBL group, $P$ values were calculated with Bonferroni corrections). The rate of cerebrovascular disease was not significantly different by Bonferroni corrections ( $P=0.058$ for the direct clipping group vs the $\mathrm{EBL}$ group). Furthermore, the rate of usage of antithrombotic agents was not significantly different by Bonferroni corrections ( $P=0.099$ for the indirect clipping group vs the EBL group). In the direct clipping group, nine patients were taking a single antithrombotic agent (aspirin 5, clopidogrel 2, edoxaban 1, and dipyridamole 1), while one received combination therapy (aspirin with clopidogrel). In the indirect clipping group, five patients were taking a single antithrombotic agent (aspirin 3, clopidogrel 1, and rivaroxaban 1), while two received combination therapy (aspirin with clopidogrel 1, and aspirin with warfarin 1). In the EBL group, 15 patients were taking a single antithrombo- 
- Table 1 Characteristics of patients who underwent endoscopic hemostasis for colonic diverticular hemorrhage with SRH

\begin{tabular}{|c|c|c|c|c|}
\hline & Direct clipping $(n=34)$ & Indirect clipping $(\mathrm{n}=\mathbf{2 8})$ & EBL $(n=31)$ & $P$ value \\
\hline Age, years, median (IQR) & $75.5(68-82.8)$ & $76(65.8-82)$ & $72(67-86.5)$ & $0.757^{1}$ \\
\hline Sex, male, n (\%) & $21(61.8)$ & $15(53.6)$ & $15(48.4)$ & $0.567^{2}$ \\
\hline \multicolumn{5}{|l|}{ Comorbidity, n (\%) } \\
\hline - Hypertension & $20(58.8)$ & $14(50.0)$ & $20(64.5)$ & $0.541^{2}$ \\
\hline - Hyperlipidemia & $5(14.7)$ & $1(3.6)$ & $4(12.9)$ & $0.342^{2}$ \\
\hline - Diabetes mellitus & $3(8.8)$ & $3(10.7)$ & $11(39.3)$ & $0.014^{2}$ \\
\hline - Chronic kidney disease & $4(11.8)$ & $2(7.1)$ & $1(3.2)$ & $0.491^{2}$ \\
\hline - Heart disease & $3(8.8)$ & $5(17.9)$ & $8(25.8)$ & $0.19^{2}$ \\
\hline - Cerebrovascular disease & $2(5.9)$ & $4(14.3)$ & $9(29.0)$ & $0.045^{2}$ \\
\hline Usage of antithrombotic agents, $n$ (\%) & $10(29.4)$ & $7(25.0)$ & $17(54.8)$ & $0.039^{2}$ \\
\hline - Single agent & 9 & 5 & 15 & \\
\hline - Combination use & 1 & 2 & 2 & \\
\hline Usage of NSAIDs, n (\%) & $8(23.5)$ & $8(28.6)$ & $14(45.2)$ & $0.185^{2}$ \\
\hline Usage of steroids, n (\%) & $1(2.9)$ & $1(3.6)$ & $0(0)$ & $0.754^{2}$ \\
\hline Previous history of colonic diverticular hemorrhage, $n$ (\%) & $19(55.9)$ & $10(35.7)$ & $18(58.1)$ & $0.178^{2}$ \\
\hline $\mathrm{Hb}$ on admission, $\mathrm{g} / \mathrm{dL}$, median (IQR) & $11(9.2-12.8)$ & $11.8(9.1-12.6)$ & $12.1(10.2-13.7)$ & $0.1^{1}$ \\
\hline Shock index on admission, median (IQR) & $0.64(0.51-0.75)$ & $0.63(0.57-0.78)$ & $0.64(0.54-0.82)$ & $0.952^{1}$ \\
\hline
\end{tabular}

tic agent (aspirin 4, clopidogrel 4, rivaroxaban 4, warfarin 2, and apixaban 1), while 2 received combination therapy (aspirin with cilostazol 1, and aspirin with clopidogrel 1).

\section{Clinical outcomes of patients who underwent endoscopic hemostasis for colonic diverticular hemorrhage with SRH}

Clinical outcomes of direct clipping, indirect clipping, and EBL for treatment of colonic diverticular hemorrhage are shown in - Table 2. A flowchart of treatment results is shown in > Fig. 3. Initial therapy successfully achieved immediate hemostasis without any procedural complications in all groups. After initial therapy, no complications occurred in any group. Location of hemorrhage, time to discharge after initial hemostasis, and units of packed RBCs were not significantly different between the three groups. The rate of active bleeding was significantly lower in the direct clipping group $(P=0.006$ for the direct clipping group vs the indirect clipping group, $P$ values were calculated with Bonferroni corrections). Total procedure time was longer in the $\mathrm{EBL}$ group ( $P=0.019$ for the direct clipping group vs the EBL group, $P$ values were calculated with Bonferroni corrections). Time to hemostasis after identification of bleeding site was longer in the EBL group $(P<0.001$ for the direct clipping group vs the EBL group, $P$ values were calculated with Bonferroni corrections). Rates of early rebleeding in the direct clip- ping, indirect clipping, and EBL groups were 5.9\% (2/34: $95 \%$ $\mathrm{Cl}, 0.7 \%-19.7 \%), 35.7 \%(10 / 28: 95 \% \mathrm{Cl}, 18.6 \%-55.9 \%)$, and $6.5 \%$ (2/31: $95 \% \mathrm{Cl}, 0.8 \%-21.4 \%)$, respectively $(P=0.006$ for the direct clipping group vs the indirect clipping group, $P=1$ for the direct clipping group vs the EBL group, $P$ values were calculated with Bonferroni corrections). Four patients in the indirect clipping group received an initial injection for diverticula with active bleeding, and one had early rebleeding.

\section{Annual changes in endoscopic hemostasis and rebleeding cases}

Annual changes in endoscopic hemostasis and rebleeding cases are shown in $\downarrow$ Table 3 . Direct clipping slightly increased from 2015, while indirect clipping slightly decreased from 2016. Our institution introduced EBL in 2016. EBL has been increasing every year.

\section{Characteristics of early rebleeding cases after hemostasis}

Characteristics of early rebleeding cases after hemostasis are shown in $>$ Table 4.

Two patients (5.9\%) in the direct clipping group had early rebleeding and underwent EBL ( $\mathbf{F i g . 3}$ ). No further bleeding occurred after repeat therapy, and neither surgical nor angiographic therapy was required. Ten patients (35.7\%) in the indir- 
Table2 Clinical outcomes of patients who underwent endoscopic hemostasis for colonic diverticular hemorrhage with SRH.

\begin{tabular}{|c|c|c|c|c|}
\hline & $\begin{array}{l}\text { Direct clipping } \\
(n=34)\end{array}$ & $\begin{array}{l}\text { Indirect clipping } \\
(\mathrm{n}=28)\end{array}$ & EBL $(n=31)$ & $P$ value \\
\hline $\mathrm{SRH}(\mathrm{AB} / \mathrm{NBVV}$ or $\mathrm{AC}), \mathrm{n}$ & $13 / 21$ & $22 / 6$ & $21 / 10$ & $0.004^{1}$ \\
\hline Location (proximal: C, A, T/ distal: D, S), n & $29 / 5$ & $19 / 9$ & $21 / 10$ & $0.181^{1}$ \\
\hline Bleeding point in the diverticulum (dome/neck/unconfirmed), $\mathrm{n}$ & $30 / 3 / 1$ & $6 / 0 / 22$ & $14 / 2 / 15$ & \\
\hline Total procedure time ${ }^{2}$, min, median (IQR) & $34(26.3-52)$ & $31.5(20.8-55.3)$ & $51(38-72.5)$ & $0.012^{3}$ \\
\hline $\begin{array}{l}\text { Time to hemostasis after identification of the bleeding site, min, } \\
\text { median (IQR) }\end{array}$ & $9(5.5-13)$ & $6(3.8-11.3)$ & $24(14-31.5)$ & $<0.001^{3}$ \\
\hline Early rebleeding ${ }^{4}, \mathrm{n}(\%)$ & $2(5.9)$ & $10(35.7)$ & $2(6.5)$ & $0.003^{1}$ \\
\hline Time to discharge after initial hemostasis, day, median (IQR) & $7(5-8)$ & $6.5(6-9)$ & $5(4-7)$ & $0.1^{5}$ \\
\hline Units of PRBCs, median (IQR) & $0(0-2)$ & $0(0-4)$ & $0(0-0)$ & $0.195^{5}$ \\
\hline Complications, n & 0 & 0 & 0 & $1^{1}$ \\
\hline \multicolumn{5}{|c|}{$\begin{array}{l}\text { SRH, stigmata of recent hemorrhage; AB, active bleeding; NBVV, non-bleeding visible vessel; AC, adherent clot; C, cecum; A, ascending colon; T, transverse colon; D, } \\
\text { descending colon; S, sigmoid colon; IQR, interquartile range; PRBCS, packed red blood cells; EBL, endoscopic band ligation. } \\
1 \text { Fisher's exact test } \\
2 \text { The total procedure time is defined as the total time from the start to end of colonoscopy } \\
{ }^{3} \text { One-way analysis of variance } \\
{ }^{4} \text { Early rebleeding is defined as rebleeding within } 30 \text { days of initial hemostasis } \\
{ }^{5} \text { Welch's test }\end{array}$} \\
\hline
\end{tabular}

- Table 3 Annual changes in endoscopic hemostasis and rebleeding.

\begin{tabular}{|c|c|c|c|c|c|c|}
\hline \multicolumn{7}{|c|}{ Endoscopic hemostasis } \\
\hline Year & 2013 & 2014 & 2015 & 2016 & 2017 & 2018 \\
\hline Direct clipping, $n$ & 0 & 3 & 5 & 11 & 5 & 10 \\
\hline Indirect clipping, $\mathrm{n}$ & 5 & 9 & 7 & 4 & 2 & 1 \\
\hline EBL, $n$ & 0 & 0 & 0 & 5 & 10 & 16 \\
\hline \multicolumn{7}{|c|}{ Rebleeding cases according to endoscopic hemostasis } \\
\hline Year & 2013 & 2014 & 2015 & 2016 & 2017 & 2018 \\
\hline Direct clipping, $n$ & 0 & 0 & 0 & 0 & 1 & 1 \\
\hline Indirect clipping, n & 2 & 2 & 3 & 2 & 0 & 1 \\
\hline EBL, $n$ & 0 & 0 & 0 & 0 & 2 & 0 \\
\hline
\end{tabular}

ect clipping group had early rebleeding. Although seven patients were managed conservatively or endoscopically, TAE or colectomy was performed on three patients because of uncontrollable hemorrhage ( $\mathbf{F i g . 3}$ ). Two patients $(6.5 \%)$ in the EBL group had early rebleeding. TAE was performed on one patient. In the EBL group, no further bleeding occurred after repeat therapy ( $\triangleright$ Fig. 3 ).

\section{Risk factors associated with early rebleeding after endoscopic hemostasis}

Multilevel logistic regression analysis was performed to verify the influence of endoscopic hemostasis on early rebleeding ( $\triangleright$ Table 5). We adjusted for age, sex, use of antithrombotic agents and NSAIDs, and SRH (active bleeding). Only indirect clipping was identified as an independent risk factor for early rebleeding after endoscopic hemostasis (OR, 12.7; $95 \% \mathrm{Cl}$ 2.02-79.4; $P=0.0067)$. 
- Table 4 Characteristics of recurrent bleeding and non-recurrent bleeding groups after endoscopic hemostasis.

\begin{tabular}{|c|c|c|c|}
\hline & $\begin{array}{l}\text { Non-recurrent bleeding } \\
(n=79)\end{array}$ & $\begin{array}{l}\text { Recurrent bleeding } \\
(n=14)\end{array}$ & $P$ value \\
\hline Age, years, median (IQR) & $75(66.5-82.5)$ & $78(69.3-85.3)$ & 0.572 \\
\hline Sex, male, n (\%) & $45(57.0)$ & $6(42.9)$ & 0.39 \\
\hline \multicolumn{4}{|l|}{ Comorbidity, n (\%) } \\
\hline - Hypertension & $48(60.8)$ & $6(42.9)$ & 0.248 \\
\hline - Hyperlipidemia & $9(11.4)$ & $1(7.1)$ & 1 \\
\hline - Diabetes mellitus & $17(21.5)$ & $0(0)$ & 0.065 \\
\hline - Chronic kidney disease & $7(8.9)$ & $0(0)$ & 0.589 \\
\hline - Heart disease & $15(19.0)$ & $1(7.1)$ & 0.45 \\
\hline - Cerebrovascular disease & $12(15.2)$ & $3(21.4)$ & 0.693 \\
\hline Usage of antithrombotic agents, n (\%) & $28(35.4)$ & $6(42.9)$ & 0.764 \\
\hline Usage of NSAIDs, n (\%) & $25(31.6)$ & $5(35.7)$ & 0.764 \\
\hline Usage of steroids, n (\%) & $2(2.5)$ & $0(0)$ & 1 \\
\hline Previous history of colonic diverticular hemorrhage, $n$ (\%) & $40(50.6)$ & $7(50.0)$ & 1 \\
\hline \multicolumn{3}{|l|}{ Endoscopic hemostasis, n (\%) } & \multirow{4}{*}{0.003} \\
\hline - Direct clipping & $32(40.5)$ & $2(14.3)$ & \\
\hline - Indirect clipping & $18(22.8)$ & $10(71.4)$ & \\
\hline - EBL & $29(36.7)$ & $2(14.3)$ & \\
\hline $\mathrm{SRH}(\mathrm{AB} / \mathrm{NBVV}$ or $\mathrm{AC}), \mathrm{n}$ & $44 / 35$ & $12 / 2$ & 0.041 \\
\hline Location (proximal: C, A, T/ distal: D, S), n & $60 / 19$ & $9 / 5$ & 0.343 \\
\hline Bleeding point in the diverticulum (dome/neck/unconfirmed), n & $44 / 5 / 30$ & $6 / 0 / 9$ & 0.417 \\
\hline Total procedure time ${ }^{1}$, min, median (IQR) & $40(29-57)$ & $28(17.3-63)$ & 0.429 \\
\hline Time to hemostasis after identification of the bleeding site, min, median (IQR) & $12(7-19)$ & $9.5(3.5-13)$ & 0.247 \\
\hline
\end{tabular}

\section{Discussion}

The current study showed two important clinical issues: the early rebleeding rate was as low in the direct clipping group as that in the EBL group, but was higher in the indirect clipping group than in the other groups.

In the current study, the early rebleeding rate with direct placement was $5.9 \%$. This is lower than the rates reported in a previous systematic review and meta-analysis [25], with rates of $19 \%$ for clipping and $21 \%$ for thermal contact, which were similar to that for EBL ( $9 \%)$. The early rebleeding rates of patients treated with endoclips were previously reported to be between $0 \%$ and $50 \%$, which is a wide range $[13,17,18,26-$ 32]. We speculate that these differences in early rebleeding rates following endoclips depend on whether endoclips are placed directly on vessels. Hemostasis with direct clip placement is sometimes considered to be difficult [22-26]. The following factors complicate direct clip placement: 1 ) endoscopic observations in colonic diverticula; 2) insertion of endoclips into colonic diverticula; and 3) stability of the endoscope. We attempted to overcome these issues using the following strategies. To improve endoscopic visualization of colonic diverticula and endoscope stability, we observed a colonic diverticulum under full water immersion using a water-jet scope with a tip hood [21]. Water immersion observations are advantageous because water immersion significantly improves endoscopic visualization and water pressure dilates a colonic diverticulum without insufflation. To facilitate insertion of endoclips into the diverticulum, we placed an open endoclip into the forceps hole of the endoscope, which reduced the width of the endoclip ( Fig.4). This step facilitated insertion of the endoclip into the colonic diverticulum. We also used a longer tip hood (approximately $7 \mathrm{~mm}$ ), which enables rotation of an endoclip in the tip hood and more accurate placement. These devices make it easier to place endoclips directly ( $\mathbf{V}$ Video 2 ). We introduced these devices in 2016. The proportion of direct clip 


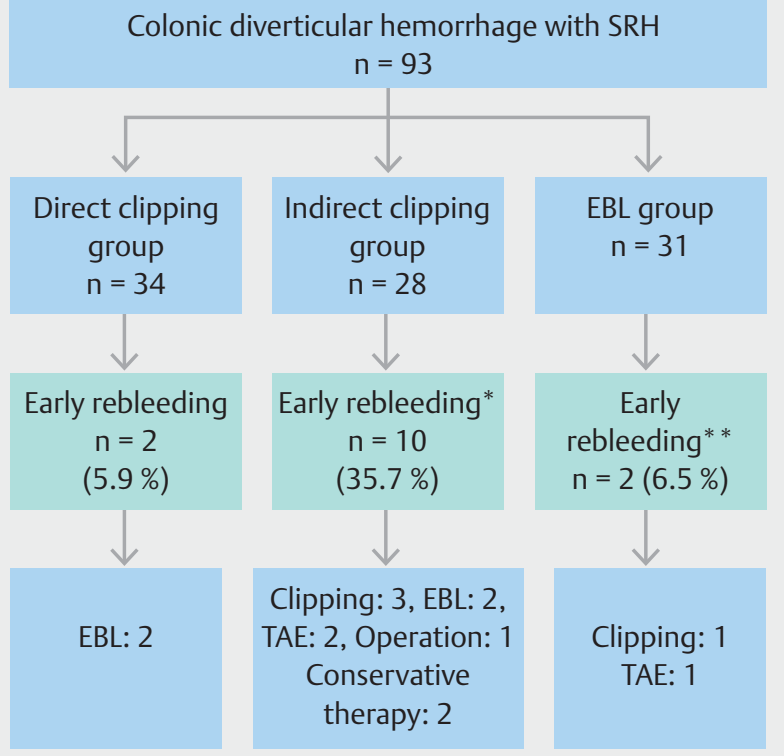

- Fig. 3 Flowchart of treatment results. SRH, stigmata of recent hemorrhage; EBL, endoscopic band ligation; TAE, transcatheter arterial embolization; Early rebleeding, recurrent bleeding within 30 days of treatment. ${ }^{*} P=0.006$ for the direct clipping group vs the indirect clipping group; ${ }^{*} P=1$ for the direct clipping group vs the EBL group. $P$ values were calculated with Bonferroni corrections.

placement increased to $40.6 \%$ (26/64: between 2016 and 2018) from 24.1\% (7/29: between 2013 and 2015) (> Table 3).

In the current study, two patients in the direct clipping group had early rebleeding. In one of these patients, direct clip placement was performed for massive active bleeding ( Fig.5a). Although bleeding was stopped by clipping ( $\mathbf{F i g}$. 5b), rebleeding occurred 16 hours later. Colonoscopy was performed, and an exposed vessel with a clot was observed beside the endoclips ( $\mathbf{F i g . 5 c}$ ). The diverticulum with endoclips was pulled via suction into the cup of the endoscopic ligator, and the elastic O-ring was released ( $\triangleright$ Fig. $\mathbf{5 d}$ ). This case suggested that the endoclips did not capture the bleeding source, and also that direct clip placement is not recommended for massive active bleeding because of the poor visual field.

In the current study, the rate of active bleeding was significantly lower in the direct clipping group, which may have contributed to the low rate of early rebleeding in the direct clipping. However, the multilevel logistic regression analysis to identify independent risk factors associated with early rebleeding showed that active bleeding was not a risk factor for early bleeding ( $>$ Table 5: $P=0.14$ ).

On the other hand, the early rebleeding rate in the indirect clipping group was high (35.7\%: 10/28). The reason for this was that the bleeding source was not captured by indirect clip placement. Ishi et al. reported that the early rebleeding rate of patients treated with endoclips was $34 \%$ (30 out of 87 cases); indirect placement in a zipper manner was performed on $85 \%$ of patients. Indirect clip placement does not always achieve complete hemostasis because of the arcades of arteries from the neck that join and form the artery in the base of the diverticulum $[13,24,33]$. These findings suggest that indirect placement of hemoclips for bleeding diverticula is ineffective for hemostasis. Moreover, Kume et al. reported a case of sepsis caused by indirect placement of endoclips for colon diverticular bleeding [34]; a diverticulum with continuous arterial spurting was closed with endoclips in a zipper manner, and the patient developed sepsis on the next day. This case report suggests that a seamed diverticulum with active bleeding permits bacteria to invade blood vessels. Therefore, indirect clip placement is not recommended from the viewpoint of effectiveness and complications.

Incidence of diverticular hemorrhage has been increasing with growing use of antithrombotic drugs in elderly patients [4-7]. In the current study, 37.6\% (35/93) of subjects were older than 80 years. If complications occur in these patients, they may become severe. AEs such as colonic diverticulitis and perforation after EBL have been reported, albeit rarely $[14,15]$.

- Table 5 Multilevel logistic regression analysis to identify independent risk factors associated with early rebleeding.

\begin{tabular}{|c|c|c|c|}
\hline & Odds ratio & $95 \% \mathrm{Cl}$ & $P$ value \\
\hline Age & 0.998 & $0.93-1.07$ & 0.948 \\
\hline Sex (Male) & 0.457 & $0.11-1.96$ & 0.291 \\
\hline Usage of antithrombotic agents & 2.67 & $0.587-12.2$ & 0.204 \\
\hline Usage of NSAIDs & 1.22 & $0.287-5.18$ & 0.789 \\
\hline SRH (active bleeding) & 3.83 & $0.644-22.8$ & 0.14 \\
\hline \multicolumn{4}{|l|}{ Endoscopic hemostasis } \\
\hline EBL & 1 & & \\
\hline Direct clipping & 1.91 & $0.216-16.8$ & 0.561 \\
\hline Indirect clipping & 12.7 & $2.02-79.4$ & 0.0067 \\
\hline
\end{tabular}




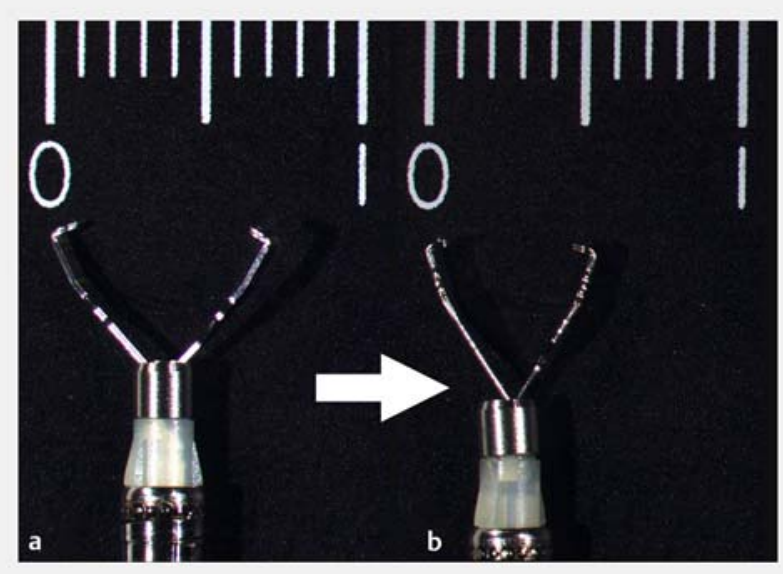

- Fig. 4 a An open endoclip (HX-610-090S; EZ CLIP, Olympus Optical Company Ltd.). b After the open endoclip is placed into the forceps hole of the endoscope, the width of the endoclip becomes narrower.

Akutsu et al. evaluated efficacy and safety of EDSL in patients with colonic diverticular bleeding without severe comorbidities. In that study [35], one of 101 patients treated with EDSL developed diverticulitis. These findings suggest that the safety of ligation methods, such as EBL and EDSL, for patients with severe comorbidities remains unclear. Therefore, treatment of these patients needs to be minimally invasive.

The endoclip approach offers the theoretical advantage of causing less damage to adjacent tissues [17, 18,36]. Moreover, endoclips are cheaper than EBL and EDSL. When rebleeding occurs after direct clip placement, the bleeding point can be treated with EBL ( $>$ Fig.5). Therefore, direct clip placement is acceptable as the first choice for colonic diverticulum hemorrhage. At our institution, direct clip placement has been the first choice for colonic diverticulum bleeding in recent years.

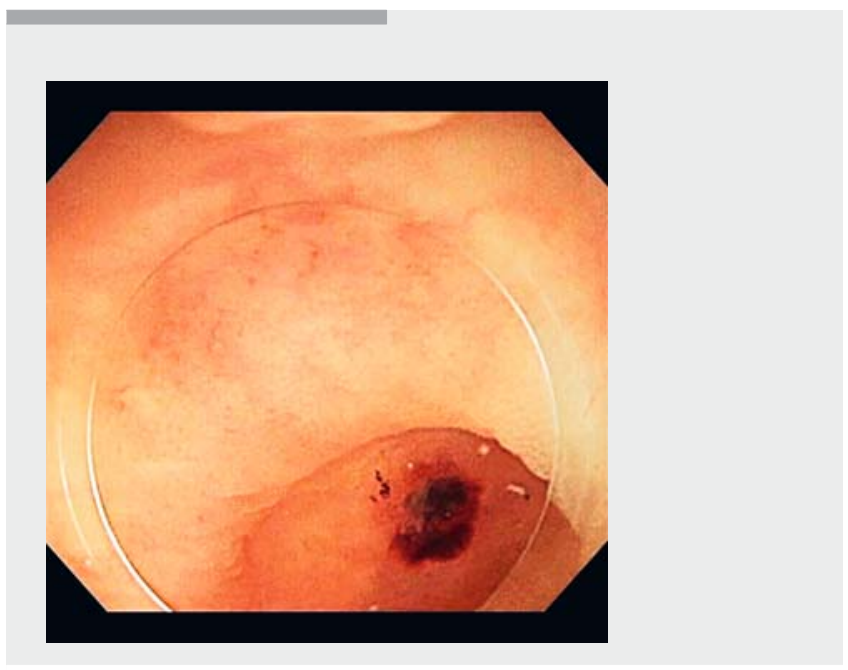

$\nabla$ Video 2 Devices for direct clip placement.

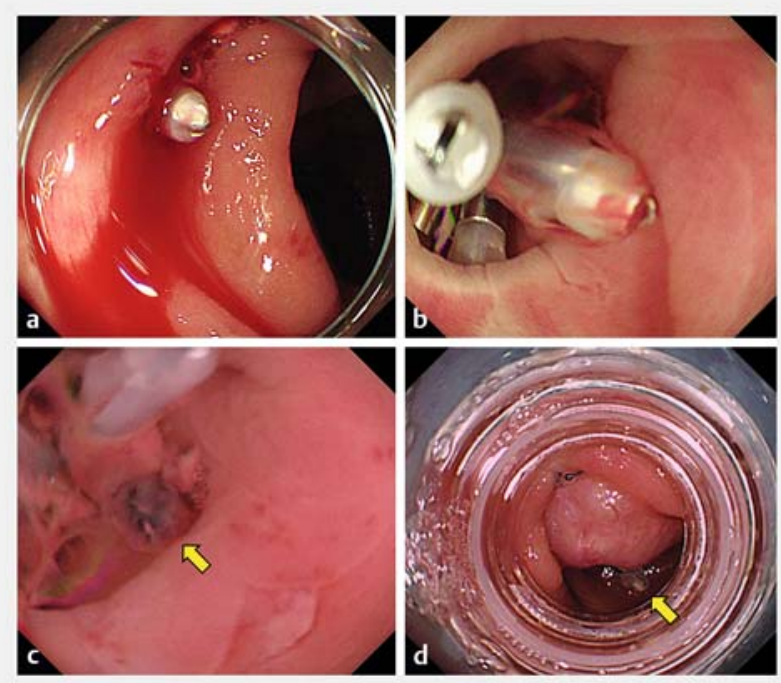

- Fig. 5 a Active bleeding from the colonic diverticulum. b Bleeding was stopped after direct clip placement. c An exposed vessel with a clot beside the endoclips (yellow arrow). $\mathbf{d}$ The diverticulum was pulled via suction into the cup of the endoscopic ligator, and the elastic O-ring was released. The yellow arrow indicates the diverticulum with endoclips after EBL.

The overall rebleeding rate in our institution was lower between 2016 and 2018 (10.9\%: 7/64) than between 2013 and 2015 (24.1\%: 7/29) ( Table 3). These results indicate that the correct strategy to achieve hemostasis was selected. A safe and cost-effective treatment may be selected by evaluating the form of the diverticulum, maneuverability of the colonoscope, and condition of the bleeding site.

The current study has several limitations. One of the main limitations that need to be addressed is that we treated bleeding without standardization. Furthermore, this was a non-randomized retrospective study that involved some selection bias. We distinguished between direct and indirect clip placement using endoscopic reports and images from colonoscopy. Selection bias for judgements is also a major issue. Decision-making and procedure skills must have differed to some extent among endoscopists. In the future, we intend to conduct a retrospective multicenter study with a larger number of patients.

\section{Conclusion}

In summary, direct clip placement is acceptable as the first treatment choice for colonic diverticular hemorrhage. When direct placement of endoclips is not possible, a ligation method such as EBL and EDSL needs to be performed instead of indirect clipping.

\section{Competing interests}

None 


\section{References}

[1] Strate LL, Ayanian JZ, Kotler G et al. Risk factors for mortality in lower intestinal bleeding. Clin Gastroenterol Hepatol 2008; 6: 1004-1010

[2] Chaudhry V, Hyser M], Gracias VH et al. Colonoscopy: the initial test for acute lower gastrointestinal bleeding. Am Surg 1998; 64: 723728

[3] Longstreth GF. Epidemiology and outcome of patients hospitalized with acute lower gastrointestinal hemorrhage: a population-based study. Am J Gastroenterol 1997; 92: 419-424

[4] Miura S, Kodaira S, Shatari T et al. Recent trends in diverticulosis of the right colon in Japan: retrospective review in a regional hospital. Dis Colon Rectum 2000; 43: 1383-1389

[5] Ohi G, Minowa K, Oyama T et al. Changes in dietary fiber intake among Japanese in the 20th century: a relationship to the prevalence of diverticular disease. Am J Clin Nutr 1983; 38: 115-121

[6] Nagata N, Niikura R, Aoki T et al. Lower Gl bleeding risk of nonsteroidal anti-inflammatory drugs and antiplatelet drug use alone and the effect of combined therapy. Gastrointest Endosc 2014; 80: 11241131

[7] Hreinsson JP, Gumundsson S, Kalaitzakis E et al. Lower gastrointestinal bleeding: incidence, etiology, and outcomes in a populationbased setting. Eur J Gastroenterol Hepatol 2013; 25: 37-43

[8] McGuire HH Jr. Bleeding colonic diverticula. A reappraisal of natural history and management. Ann Surg 1994; 220: 653-656

[9] Farrell J], Friedman LS. Gastrointestinal bleeding in the elderly. Gastroenterol Clin North Am 2001; 30: 377-407

[10] Tan KK, Nallathamby V, Wong D et al. Can superselective embolization be definitive for colonic diverticular hemorrhage? An institution's experience over 9 years J Gastrointest Surg 2010; 14: 112-118

[11] Aytac E, Stocchi L, Gorgun E et al. Risk of recurrence and long-term outcomes after colonic diverticular bleeding. Int J Colorectal Dis 2014; 29: 373-378

[12] Jensen DM, Ohning GV, Kovacs TO et al. Natural history of definitive diverticular hemorrhage based on stigmata of recent hemorrhage and colonoscopic Doppler blood flow monitoring for risk stratification and definitive hemostasis. Gastrointest Endosc 2016; 83: 416-423

[13] Setoyama T, Ishii N, Fujita Y. Enodoscopic band ligation (EBL) is superior to endoscopic clipping for the treatment of colonic diverticular hemorrhage. Surg Endosc 2011; 25: 3574-3578

[14] Ishii N, Fujita Y. Colonic Diverticulitis After endoscopic band ligation performed for colonic diverticular hemorrhage. ACG Case Rep J 2015; 2: $218-220$

[15] Takahashi S, Inaba T, Tanaka N. Delayed perforation after endoscopic band ligation for treatment of colonic diverticular bleeding. Dig Endosc 2016; 28: 484

[16] Hokama A, Uehara T, Nakayoshi T et al. Utility of endoscopic hemoclipping for colonic diverticular bleeding. Am J Gastroenterol 1997; 92: 543-546

[17] Yen EF, Ladabaum U, Muthusamy VR et al. Colonoscopic treatment of acute diverticular hemorrhage using endoclips. Dig Dis Sci 2008; 53 : 2480-2485

[18] Simpson PW, Nguyen MH, Lim JK et al. Use of endoclips in the treatment of massive colonic diverticular bleeding. Gastrointest Endosc 2004; 59: 433-437
[19] Jensen DM, Machicado GA, Jutabha R et al. Urgent colonoscopy for the diagnosis and treatment of severe diverticular hemorrhage. $\mathrm{N}$ Engl J Med 2000; 342: 78-82

[20] Foutch PG. Diverticular bleeding: are nonsteroidal anti-inflammatory drugs risk factors for hemorrhage and can colonoscopy predict outcome for patients? Am J Gastroentero 1995; 90: 1779-1784

[21] Kishino T, Kitaichi T, Kanemasa K. Usefulness of water immersion observations to identify the stigmata of hemorrhage in colonic diverticular bleeding. Dig Endosc 2018; 30: 121-122

[22] Ishii N, Itoh T, Uemura M et al. Endoscopic band ligation with a waterjet scope for the treatment of colonic diverticular hemorrhage. Dig Endosc 2010; 22: 232-235

[23] Ishii N, Uemura M, Itoh T et al. Endoscopic band ligation for the treatment of bleeding colonic and ileal diverticula. Endoscopy 2010; 42: E82-E83

[24] Ishii N, Setoyama T, Deshpande GA et al. Endoscopic band ligation for colonic diverticular hemorrhage. Gastrointest Endosc 2012; 75: 382387

[25] Ishii N, Omata F, Nagata N et al. Effectiveness of endoscopic treatments for colonic diverticular bleeding. Gastrointest Endosc 2018; 87: 58-66

[26] Ishii N, Hirata N, Omata F et al. Location in the ascending colon is a predictor of refractory colonic diverticular hemorrhage after endoscopic clipping. Gastrointest Endosc 2012; 76: 1175-1181

[27] Kaltenbach T, Watson R, Shah J et al. Colonoscopy with clipping is useful in the diagnosis and treatment of diverticular bleeding. Clin Gastroenterol Hepatol 2012; 10: 131-137

[28] Fujino Y, Inoue Y, Onodera M et al. Risk factors for early re-bleeding and associated hospitalization in patients with colonic diverticular bleeding. Colorectal Dis 2013; 15: 982-986

[29] Sugiyama T, Hirata Y, Kojima Y et al. Efficacy of contrast-enhanced computed tomography for the treatment strategy of colonic diverticular bleeding. Intern Med 2015; 54: 2961-2967

[30] Nagata N, Niikura R, Aoki T et al. Risk factors for adverse in-hospital outcomes in acute colonic diverticular hemorrhage. World J Gastroenterol 2015; 21: 10697-10703

[31] Kumar A, Artifon E, Chu A et al. Effectiveness of endoclips for the treatment of stigmata of recent hemorrhage in the colon of patients with acute lower gastrointestinal tract bleeding. Dig Dis Sci 2011; 56: 2978-2986

[32] Couto-Worner I, Gonzalez-Conde B, Estevez-Prieto E et al. Colonic diverticular bleeding: urgent colonoscopy without purging and endoscopic treatment with epinephrine and hemoclips. Rev Esp Enferm Dig 2013; 105: 495-498

[33] Shimamura Y, Ishii N, Omata F et al. Endoscopic band ligation for coIonic diverticular bleeding: possibility of standardization. Endosc Int Open 2016; 4: E233-E237

[34] Kume K, Yamasaki M, Yoshikawa I. Sepsis caused by endoscopic clipping for colonic diverticular bleeding: A rare complication. World ] Gastroenterol 2009; 15: 3817-3818

[35] Akutsu D, Narasaka T, Kobayashi K et al. Newly developed endoscopic detachable snare ligation therapy for colonic diverticular hemorrhage: a multicenter phase II trial (with videos). Gastrointest Endosc 2018; 88: 370-377

[36] Hokama A, Kishimoto K, Kinjo F et al. Endoscopic clipping in the lower gastrointestinal tract. World J Gastrointest Endosc 2009; 1: 7-11 